\section{Genetic Differentiation of Portuguese Tea Plant using RAPD Markers}

\author{
S. Jorge ${ }^{1}$ and M.C. Pedroso \\ Faculdade de Ciências da Universidade de Lisboa, Departamento de Biologia \\ Vegetal, Centro de Biotecnologia Vegetal, Bloco C2, Piso 1, Campo Grande, \\ 1749-016 Lisbon, Portugal
}

\section{D.B. Neale and G. Brown \\ Department of Environmental Horticulture, University of California, Davis, CA 95616}

Additional index words. Camellia sinensis, genetic diversity, molecular markers, RAPD
analysis

\begin{abstract}
Random amplified polymorphic DNA(RAPD) analysis was used to estimate genetic similarities between Portuguese Camellia sinensis (L.) O. Kuntze (tea plant) accessions and those obtained from the germplasm collections from the Tea Research Foundation of Kenya and from the National Research Institute of Vegetables, Ornamental Plants, and Tea of Japan. The accessions studied are taxonomically classified as $C$. sinensis, var. sinensis, var. assamica, or ssp. lasiocalyx. A set of 118 ten-base arbitrary primers was tested, of which 25 produced informative, reproducible, and polymorphic banding patterns. These primers were used to amplify DNA from 71 tea plant accessions and produced a total of 282 bands, of which 195 were polymorphic. The phenotypic frequencies were calculated using Shannon's Index and employed in estimating genetic diversity within tea plant populations. Our study demonstrates that tea plant populations, including the Portuguese tea plants, show considerable genetic variability. From the UPGMA cluster analysis based on a matrix using the Jaccard coefficient, it was possible to distinguish the Portuguese tea plants from the remaining accessions. The RAPD markers discriminated the three $C$. sinensis varieties. Moreover, within each variety cluster, subclusters formed according to geographic distribution. The RAPD analysis also separated the commercially cultivated tea plants from the Taiwanese wild tea plants. The present results show that RAPD analysis constitutes a good method to estimate genetic diversity within $C$. sinensis, and to differentiate $C$. sinensis accessions according to taxonomic variety and geographical distribution.
\end{abstract}

Camellia sinensis (L.) O. Kuntze, the tea plant, is the most economically important species of the genus Camellia (Wachira et al., 1995). Tea is the second most consumed beverage in the world after water (Weisburger, 1997), and recent literature strongly emphasizes its value in disease prevention and as a key component of daily diets (Mukhtar and Ahmad, 1999, 2000; Weisburger, 1997).

The tea plant, originally from China, probably reached Europe through Portu-

\footnotetext{
Received for publication 25 June 2002. Accepted for publication 4 Feb. 2003. Research conducted in partial fulfillment of a $\mathrm{PhD}$ in biology by S. Jorge and supported by the Foundation for Science and Technology (through the fellowship PRAXIS $\mathrm{XXI} / \mathrm{BD} / 13870 / 97)$ and by the European Social Fund (FSE) under the ambit of the 3rd Board of Communitarian Support (III QCA). We thank Dr. Wachira (The Tea Research Foundation of Kenya), Prof. Matsumoto (National Research Institute of Vegetables, Ornamental Plant and Tea of Japan), Eng. Mota (Plantações de Chá Gorreana, Azores, Portugal), Dr. Gil de Seabra (O'Porto, Portugal); and also Dr. Serra Lopes and Eng. Monjardino (Parque da Pena, Sintra, Portugal) for the kind gift of $C$. sinensis leaves; and Dr. Tenreiro and Dr. Durzan for the critical reading of the manuscript.

${ }^{1}$ To whom correspondence should be addressed; e-mail address: smjorge@fc.ul.pt
}

guese and Dutch sailors in the 16th century. In Portugal, $C$. sinensis has been present since the beginning of the 19th century, both in the Archipelago of Azores (S. Miguel Island) and the mainland, where its culture is documented (Ferrão, 1992). Today it is still possible to find evidence of these plants on the mainland at "The Peak of Tea" (Alto do Chá) in the Natural Park of Sintra (Parque da Pena, Sintra) and in some botanical gardens (Jardim Botânico da Faculdade de Ciências de Lisboa and Jardim de Garcia da Horta, Lisbon). The cultivation and processing of $C$. sinensis for commercial purposes in Portugal takes place only in the Archipelago of Azores (S. Miguel Island) on a small, family-owned property, the Gorreana Tea Plantation (Plantações de Chá Gorreana) (Amaral, 2001).

The taxonomy of $C$. sinensis is based on vegetative characteristics. Although vegetative characters show a high degree of variation and plasticity, leaf aspects, such as shape, length, and margins, continue to be the basis for tea plant classification (Banerjee, 1992). By this method, Kitamura (1950) and Sealy (1958) recognized two botanical varieties of $C$. sinensis $(\mathrm{L}$.), the variety China, Camellia sinensis var. sinensis (L.), and the variety Assam, Camellia sinensis var. assamica (Masters) Kitamura. Despite several proposed changes to this classification, it is common to put all the tea plants under the name $C$. sinensis (L.) O. Kuntze, regardless of taxonomic variation. In addition, varieties China, Assam, and Cambod are often referred to as $C$. sinensis, C. assamica, and C.assamica ssp. lasiocalyx, respectively (Banerjee, 1992; Paul et al., 1997).

Genetic diversity in $C$. sinensis has been estimated using primarily morphological and agronomic characters. Recently, several biochemical and molecular techniques have been employed as an attempt to overcome problems caused by the environmental influences on vegetative characters, which make it difficult to identify distinct taxonomic groups. Magoma et al. (2000) used total green leaf catechins and the ratio of dihydroxylated to trihydroxylated catechins as biochemical markers to determine genetic variation in Kenyan tea plant germplasm. Using RFLP markers, Matsumoto et al. (1994) distinguished Assam hybrids and Japanese green tea plant cultivars with high and low catechin content and grouped Japanese green tea plants at the cultivar level. Paul et al. (1997) employed the AFLP technique to study genetic variation between and within populations of $C$. sinensis. Wachira et al. (1995) used RAPD markers to estimate the level of genetic diversity in cultivated tea and, in a later study (1997), used RAPD markers and PCR amplification of chloroplast and mitochondrial sequences to assess the relationships among cultivated tea and some wild species in the genus Camellia.

In the present study, we used random amplified polymorphic DNA (RAPD) analysis to estimate genetic similarities among Portuguese C. sinensis var. sinensis accessions and those from China, Japan, and Kenya; C. sinensis var. assamica accessions from India, Burma, Vietnam, Taiwan, and Kenya; C. assamica ssp. lasiocalyx accessions from Cambodia; and a Kenyan accession of Camellia irrawadiensis, a wild species related to the tea plant. Among the Portuguese accessions studied are the commercial cultivars from Azores, and wild tea plants from the mainland, not used for tea production.

\section{Materials and Methods}

Plant material. Silica-dried leaves of $C$. sinensis were obtained from germplasm collections of the Tea Research Foundation of Kenya (TRFK) and the National Research Institute of Vegetables, Ornamental Plants, and Tea of Japan (NIVOT). Fresh leaves from the Portuguese accessions were obtained from two botanical gardens (Jardim Botânico da Universidade de Lisboa, and Jardim de Garcia da Horta, Lisbon), from a natural park (Parque da Pena, Sintra), from the Gorreana Tea Plantation (S. Miguel Island, Azores), and also from a private collection (O'Porto). The varieties studied include 37 accessions of Assam teas, 24 Chinese teas, 2 Cambodian teas, 1 Assam hybrid, 6 Portuguese accessions of unknown variety, and 1 accession of Camellia irrawadiensis (Table 1).

DNA isolation. DNA was extracted from fresh tea leaves with the DNeasy Plant Kit (Qiagen, Valencia, Calif.) and from silica- 
Breeding, Cultivars, Rootstocks, \& Germplasm Resources

dried leaf material using the method Doyle and Doyle (1987) modified by Weising (1995). DNAconcentration was determined using the Mini-Fluorometer TKO 100 (Hoefer Scientific Instruments, San Francisco) with the calf thymus DNA standard. Samples were diluted to $1 \mathrm{ng} \cdot \mu \mathrm{L}^{-1}$ with $1 / 10 \mathrm{TE}$ buffer (Sambrook et al., 1989) and allowed a working life of 6 weeks. New stocks were made up at the end of this period or following exhaustion of stock.

RAPD assay. Operon 10-base oligonucleotide primers kits $\mathrm{A}, \mathrm{B}, \mathrm{X}, \mathrm{V}, \mathrm{W}$, and also 10 and 8 primers from kits $\mathrm{AC}$ and $\mathrm{AK}$, respectively (Qiagen Operon, Alameda, Calif.), were screened for DNA polymorphism. In total, 118 primers were tested, and the 25 informative polymorphic primers were chosen for analysis (Table 2). PCR conditions, including the concentration of template DNA, primer, dNTPs, magnesium chloride, and Taq DNA polymerase were optimized to generate RAPD profiles of high intensity and sharp bands with clear background. The $25-\mu$ Lreaction mixture contained $2.5 \mathrm{ng}$ of template DNA, $100 \mu \mathrm{M}$ each of dATP, dCTP, dGTP, and dTTP (Perkin-Elmer, Foster City, Calif.), $5 \mu \mathrm{m}$ primer, $0.25 \mathrm{U} \mathrm{Taq}$ DNA polymerase (Qiagen), $2.5 \mathrm{~mm}$ $\mathrm{MgCl}_{2}$ (Qiagen), and 1X Taq polymerase buffer (Qiagen). Amplifications were performed in a Thermal Cycler (PTC-100 Programmable Thermal Controller, M.J. Research, Waltham, Mass.) programmed for an initial denaturing period of $94^{\circ} \mathrm{C}$ for $3 \mathrm{~min}$ and then 45 cycles, each consisting of $92{ }^{\circ} \mathrm{C}$ for $1 \mathrm{~min}, 35^{\circ} \mathrm{C}$ for $1.5 \mathrm{~min}, 72^{\circ} \mathrm{C}$ for $2 \mathrm{~min}$, followed by a final extension at $72{ }^{\circ} \mathrm{C}$ for $5 \mathrm{~min}$. Samples were stored at $4{ }^{\circ} \mathrm{C}$ until analysis. Fragments generated by amplification were separated according to size by electrophoresis on $2.0 \%$ $(\mathrm{w} / \mathrm{v})$ agarose gels run in $1 \mathrm{X}$ TAE buffer for $4 \mathrm{~h}$ at $100 \mathrm{~V}$, stained with ethidium bromide, and visualized by illumination with ultraviolet light. A 100-bp DNA Ladder (Invitrogen Life Technologies, Carlsbad, Calif.) was used as the size marker. Negative controls (where the DNA sample was replaced with water) and duplicated DNA samples were included in all amplification reactions. Moreover, DNA samples from different plants of the same accession were amplified in the same PCR reaction and all the amplification reactions were repeated three times to ascertain reproducibility of bands.

Data analysis. Each polymorphic band was labelled based upon the primer code and approximate size. For example, OPV02-1550 represented the 1550-bp band amplified by primer OPV02. Bands were scored as present (1) or absent (0). Ambiguities (reactions that failed) were scored as missing data. The degree of polymorphism was quantified using Shannon's Index of phenotypic diversity, defined as:

$$
\mathrm{H}=-\Sigma p_{\mathrm{i}} \log _{2} p_{\mathrm{i}}
$$

where " $p_{\mathrm{i}}$ " is the frequency of phenotype " $\mathrm{i}$," or the frequency of each band amplified by a given primer (Zar, 1999). Averaging $\mathrm{H}$ over all primers allows calculation of diversity within populations $\left(\mathrm{H}_{0}\right)$ for each population or
Table 1. Camellia sinensis accessions used in RAPD analysis

\begin{tabular}{|c|c|c|c|c|}
\hline $\begin{array}{l}\text { Genotype } \\
\text { number }\end{array}$ & $\begin{array}{l}\text { Accession } \\
\text { code }\end{array}$ & Species and variety & Collection & Source \\
\hline$\overline{1}$ & P1 & C. sinensis var. assamica & Azores & Portugal \\
\hline 2 & P2 & C. sinensis (hybrid) & Azores & Portugal \\
\hline 3 & P3 & C. sinensis var. sinensis & Azores & Portugal \\
\hline 4 & P4 & C. sinensis (var. unknown) & Sintra & Portugal \\
\hline 5 & P5 & C. sinensis (var. unknown ) & O'Porto & Portugal \\
\hline 6 & P6 & C. sinensis (var. unknown ) & O'Porto & Portugal \\
\hline 7 & P7 & C. sinensis (var. unknown) & Garcia da Horta & Portugal \\
\hline 8 & P8 & C. sinensis (var. unknown) & Garcia da Horta & Portugal \\
\hline 9 & P9 & C. sinensis (var. unknown) & Botanical Garden & Portugal \\
\hline 10 & AK450 & C. sinensis var. assamica & India & NIVOT \\
\hline 11 & AK533 & C. sinensis var. assamica & India & NIVOT \\
\hline 12 & AK552 & C. sinensis var. assamica & India & NIVOT \\
\hline 13 & AK329 & C. sinensis var. assamica & India & NIVOT \\
\hline 14 & AK744 & C. sinensis var. assamica & India & NIVOT \\
\hline 15 & AK547 & C. sinensis var. assamica & India & NIVOT \\
\hline 16 & AK251 & C. sinensis var. assamica & India & NIVOT \\
\hline 17 & AK127 & C. sinensis var. assamica & India & NIVOT \\
\hline 18 & AK757 & C. sinensis var. assamica & India & NIVOT \\
\hline 19 & AK293 & C. sinensis var. assamica & India & NIVOT \\
\hline 20 & AK31 & C. sinensis var. assamica & India & NIVOT \\
\hline 21 & AK562 & C. sinensis var. assamica & India & NIVOT \\
\hline 22 & AK433 & C. sinensis var. assamica & India & NIVOT \\
\hline 23 & $\mathrm{Ai} 2$ & C. sinensis var. assamica & India & NIVOT \\
\hline 24 & Ai66 & C. sinensis var. assamica & India & NIVOT \\
\hline 25 & Ai104 & C. sinensis var. assamica & India & NIVOT \\
\hline 26 & Ai142 & C. sinensis var. assamica & India & NIVOT \\
\hline 27 & Stock 173 & C. sinensis var. assamica & India & NIVOT \\
\hline 28 & BUM3 & C. sinensis var. assamica & Burma & NIVOT \\
\hline 29 & BUM5 & C. sinensis var. assamicaa & Burma & NIVOT \\
\hline 30 & BUM6 & C. sinensis var. assamica & Burma & NIVOT \\
\hline 31 & Shan1-3 & C. sinensis var. assamica & Vietnam & NIVOT \\
\hline 32 & Shan1-5 & C. sinensis var. assamica & Vietnam & NIVOT \\
\hline 33 & Shan21 & C. sinensis var. assamica & Vietnam & NIVOT \\
\hline 34 & T-Yamacha75 & C. sinensis var. assamica & Taiwan & NIVOT \\
\hline 35 & T-Yamacha80 & C. sinensis var. assamica & Taiwan & NIVOT \\
\hline 36 & T-Yamacha84 & C. sinensis var. assamica & Taiwan & NIVOT \\
\hline 37 & T-Yamacha88 & C. sinensis var. assamica & Taiwan & NIVOT \\
\hline 38 & CK9 & C. sinensis var. sinensis & China & NIVOT \\
\hline 39 & CK10 & C. sinensis var. sinensis & China & NIVOT \\
\hline 40 & CK11 & C. sinensis var. sinensis & China & NIVOT \\
\hline 41 & CK12 & C. sinensis var. sinensis & China & NIVOT \\
\hline 42 & CK13 & C. sinensis var. sinensis & China & NIVOT \\
\hline 43 & CK15 & C. sinensis var. sinensis & China & NIVOT \\
\hline 44 & CK16 & C. sinensis var. sinensis & China & NIVOT \\
\hline 45 & CK17 & C. sinensis var. sinensis & China & NIVOT \\
\hline 46 & Yabukita & C. sinensis var. sinensis & Japan & NIVOT \\
\hline 47 & Tamamidori & C. sinensis var. sinensis & Japan & NIVOT \\
\hline 48 & Sayamamidori & C. sinensis var. sinensis & Japan & NIVOT \\
\hline 49 & Miyoshi & C. sinensis var. sinensis & Japan & NIVOT \\
\hline 50 & Asatsuyu & C. sinensis var. sinensis & Japan & NIVOT \\
\hline 51 & Yamatomidori & C. sinensis var. sinensis & Japan & NIVOT \\
\hline 52 & Benibanacha & C. sinensis var. sinensis & Japan & NIVOT \\
\hline 53 & ZAI 80-10 & C. sinensis var. sinensis & Japan & NIVOT \\
\hline 54 & ZAI 80-19 & C. sinensis var. sinensis & Japan & NIVOT \\
\hline 55 & ZAI $80-20$ & C. sinensis var. sinensis & Japan & NIVOT \\
\hline 56 & ZAI $80-25$ & C. sinensis var. sinensis & Japan & NIVOT \\
\hline 57 & ZAI 80-37 & C. sinensis var. sinensis & Japan & NIVOT \\
\hline 58 & ZAI 81-13 & C. sinensis var. sinensis & Japan & NIVOT \\
\hline 59 & ZAI 81-27 & C. sinensis var. sinensis & Japan & NIVOT \\
\hline 60 & $317 / 28$ & C. sinensis var. assamica & Kenya & TRFK \\
\hline 61 & $330 / 83$ & C. sinensis var. assamica & Kenya & TRFK \\
\hline 62 & $\mathrm{C} 12$ & C. sinensis var. assamica & Kenya & TRFK \\
\hline 63 & D99/10 & C. sinensis var. assamica & Kenya & TRFK \\
\hline 64 & SFS 150 & C. sinensis var. assamica & Kenya & TRFK \\
\hline 65 & S $15 / 10$ & C. sinensis var. assamica & Kenya & TRFK \\
\hline 66 & TN $14-3$ & C. sinensis var. assamica & Kenya & TRFK \\
\hline 67 & $6 / 8$ & C. sinensis var. assamica & Kenya & TRFK \\
\hline 68 & K-Purple & C. sinensis var. sinensis & Kenya & TRFK \\
\hline 69 & $301 / 6$ & C. sinensis $\mathrm{ssp}$. lasiocalyx & Cambodia & TRFK \\
\hline 70 & $301 / 4$ & C. sinensis ssp. lasiocalyx & Cambodia & TRFK \\
\hline 71 & $91 / 1$ & C. irrawadiensis & Kenya & TRFK \\
\hline
\end{tabular}


Table 2. Primers used for the detection of polymorphism in Camellia sinensis and the number of amplification products obtained.

\begin{tabular}{|c|c|c|c|}
\hline Primer & $\begin{array}{l}\text { Sequence } \\
\left(3^{\prime}-5^{\prime}\right)\end{array}$ & $\begin{array}{c}\text { Total no. of } \\
\text { reproducible bands }\end{array}$ & $\begin{array}{c}\text { Total no. of } \\
\text { polymorphic bands }\end{array}$ \\
\hline$\overline{\mathrm{OPAC}-03}$ & CACTGGCCCA & 7 & 5 \\
\hline OPAC-11 & CCTGGGTCAG & 13 & 10 \\
\hline OPW-01 & CTCAGTGTCC & 8 & 6 \\
\hline OPW-02 & ACCCCGCCAA & 13 & 9 \\
\hline OPW-05 & GGCGGATAAG & 12 & 4 \\
\hline OPW-10 & TCGCATCCCT & 12 & 8 \\
\hline OPW-11 & CTGATGCGTG & 14 & 10 \\
\hline OPW-16 & CAGCCTACCA & 9 & 6 \\
\hline OPW-17 & GTCCTGGGTT & 13 & 10 \\
\hline OPW-19 & CAAAGCGCTC & 14 & 12 \\
\hline OPAK-17 & CAGCGGTCAC & 13 & 10 \\
\hline OPAK-18 & ACCCGGAAAC & 7 & 6 \\
\hline OPA-05 & AGGGGTCTTG & 4 & 4 \\
\hline OPA-07 & GAAACGGGTG & 14 & 10 \\
\hline OPA-08 & GTGACGTAGG & 12 & 7 \\
\hline OPA-10 & GTGATCGCAG & 13 & 10 \\
\hline OPA-11 & CAATCGCCGT & 13 & 7 \\
\hline OPA-18 & AGGTGACCGT & 12 & 10 \\
\hline OPB-07 & GGTGACGCAG & 10 & 8 \\
\hline OPB-08 & GTCCACACGG & 9 & 6 \\
\hline OPB-12 & CCTTGACGCA & 12 & 8 \\
\hline OPV-02 & AGTCACTCCC & 14 & 8 \\
\hline OPV-10 & GGACCTGCTG & 11 & 7 \\
\hline OPV-12 & ACCCCCCACT & 12 & 7 \\
\hline OPV-14 & AGATCCCGCC & 11 & 7 \\
\hline Total & --- & 282 & 195 \\
\hline
\end{tabular}

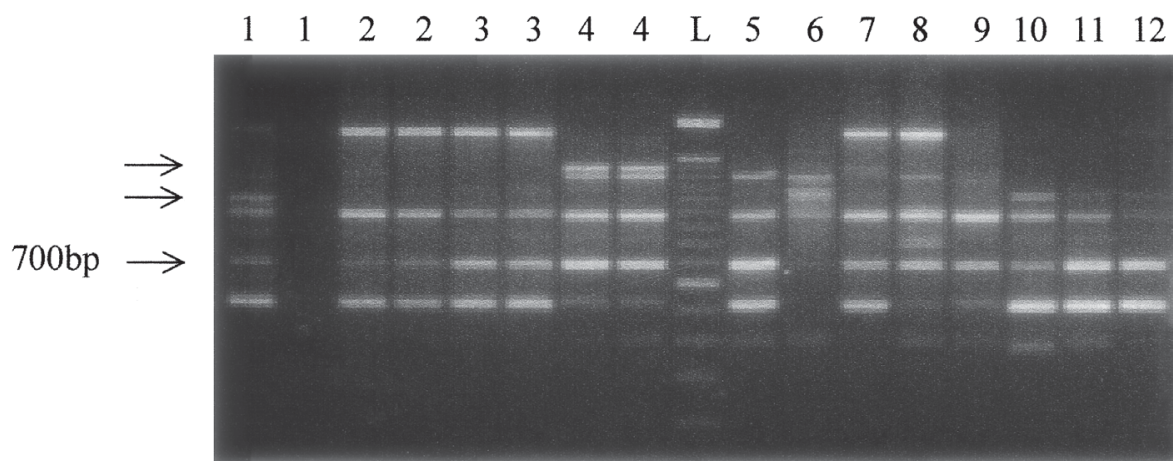

Fig. 1. Agarose-gel revealing bands amplified with primer OPB-08. L: 100-bp DNA ladder; arrows: two polymorphic bands for Portuguese accessions; lanes 1-12: genotype numbers according to Table 1. The repeated lane numbers (1-4) indicate duplicated DNA samples. The reaction in lane 2 failed in this set of assays. group. The average diversity for all populations $\left(\mathrm{H}_{\text {pop }}\right)$ is calculated as the mean of individual $\mathrm{H}_{0}$ values. The total diversity $\left(\mathrm{H}_{\text {tot }}\right)$ over " $\mathrm{n}$ " populations is calculated from phenotypic frequencies in all populations considered together (all the 71 accessions analyzed). The proportion of diversity within a population, obtained by dividing $\mathrm{H}_{\mathrm{pop}} / \mathrm{H}_{\mathrm{tot}}$, was compared to diversity between populations $\left(1-\mathrm{H}_{\text {pop }} / \mathrm{H}_{\text {tot }}\right.$ ) (Kaundun et al., 2000). Using NTSYS-pc (version 2.1, Exeter Software, Setauket, N.Y.) software, the Jaccard and Dice similarity coefficients were used to estimate the similarity among all 71 genotypes with 195 characters. The phenograms were constructed with the Unweighted Pair Group Method with Arithmetic Mean (UPGMA) clustering procedure. The cophenetic correlation values were determined to test the goodness of fit of the data clustering. Data ordination was performed by Principal Coordinate Analysis (PCOORDA), and a Minimum Spanning Tree (MST) was computed and superimposed on PCOORDA.

\section{Results}

Due to the reported sensitivity of the RAPD methodology to experimental conditions (Edwards, 1998; Sala et al., 1998), PCR amplifications were carried out under optimal standardized conditions and only highly reproducible bands were scored. From a total of 118 primers used to amplify tea plant DNA, 25 $(21 \%)$ produced polymorphic and reproducible bands. A total of 282 bands were produced, of which 195 (69\%) were scored for the analysis because they were reproducibly polymorphic. The number of polymorphic bands detected for each primer varied from 4 (primers OPW-05 and OPA-05) to 12 (primer OPW-19) with an average of 7.8 (Table 2). The amplification products obtained for primer OPB-08 are shown in Fig. 1.

The phenotypic frequencies detected with the 25 primers were calculated and used in estimating genetic diversity $(\mathrm{H})$ within each tea plant group (Table 3). The Portuguese tea plants exhibited high variability (2.35), equal to that of the Indian group. The low variability

Table 3. Estimates of genetic diversity $(\mathrm{H})$ within $C$. sinensis groups $^{2}$, averaged over all 195 polymorphic bands.

\begin{tabular}{|c|c|c|c|c|c|c|c|c|c|c|c|c|}
\hline Group & $\begin{array}{c}\text { All pop. } \\
\text { (a) }\end{array}$ & $\begin{array}{l}\text { Portugal } \\
\text { (a) }\end{array}$ & $\begin{array}{l}\text { India } \\
\text { (a) }\end{array}$ & $\begin{array}{l}\text { Burma } \\
\text { (a) }\end{array}$ & $\begin{array}{c}\text { Vietnam } \\
\text { (a) }\end{array}$ & $\begin{array}{l}\text { Taiwan } \\
\text { (a) }\end{array}$ & $\begin{array}{c}\text { China } \\
\text { (a) }\end{array}$ & $\begin{array}{c}\text { Japan } \\
\text { (a) }\end{array}$ & $\begin{array}{c}\text { Kenya } \\
\text { (a) }\end{array}$ & $\begin{array}{c}\text { Cambodia } \\
(\mathrm{a}, \mathrm{b})\end{array}$ & $\begin{array}{l}\text { var. assamica } \\
\text { (b) }\end{array}$ & $\begin{array}{c}\text { var. sinensis } \\
\text { (b) }\end{array}$ \\
\hline $\begin{array}{l}\text { No. of accessions } \\
\text { per group }\end{array}$ & 71 & 9 & 18 & 3 & 3 & 4 & 8 & 14 & 10 & 2 & 37 & 24 \\
\hline $\mathrm{H}$ range per primer & $\begin{array}{r}1.67 \\
\text { to } 3.46\end{array}$ & $\begin{array}{r}0.85 \\
\text { to } 3.22\end{array}$ & $\begin{array}{r}1.38 \\
\text { to } 3.09\end{array}$ & $\begin{array}{r}0.81 \\
\text { to } 2.87\end{array}$ & $\begin{array}{r}0.00 \\
\text { to } 2.86\end{array}$ & $\begin{array}{r}0.00 \\
\text { to } 2.60\end{array}$ & $\begin{array}{r}0.92 \\
\text { to } 3.10\end{array}$ & $\begin{array}{r}0.00 \\
\text { to } 3.12\end{array}$ & $\begin{array}{r}1.00 \\
\text { to } 2.89\end{array}$ & $\begin{array}{r}0.00 \\
\text { to } 2.32\end{array}$ & $\begin{array}{r}1.41 \\
\text { to } 3.21\end{array}$ & $\begin{array}{r}2.18 \\
\text { to } 3.29\end{array}$ \\
\hline$\underline{\mathrm{H} \text { average }}$ & 2.7 & 2.35 & 2.35 & 1.7 & 1.51 & 1.52 & 1.83 & 1.87 & 2.06 & 1.30 & 2.56 & 2.18 \\
\hline
\end{tabular}

${ }^{\mathrm{z}}$ Groups were constructed based on the geographical origin (a) and on the taxonomic variety (b). All pop. $=$ all 71 tea plant accessions considered together.

Table 4. Partitioning of the overall genetic diversity $(\mathrm{H})$ within and between tea plant groups. ${ }^{\mathrm{z}}$

\begin{tabular}{lcccc}
\hline & $\mathrm{H}_{\text {tot }}$ & $\mathrm{H}_{\text {pop }}$ & $\mathrm{H}_{\text {pop }} / \mathrm{H}_{\text {tot }}$ & $\left(\mathrm{H}_{\text {tot }}-\mathrm{H}_{\text {pop }}\right) / \mathrm{H}_{\text {tot }}$ \\
\hline Range per primer & 1.67 to 3.46 & 1.16 to 2.45 & 0.58 to 0.89 & 0.11 to 0.42 \\
Average & 2.70 & 1.93 & 0.72 & 0.28 \\
\hline${ }^{\mathrm{z}} \mathrm{H}_{\text {tot }}=$ total diversity (all 71 accessions considered together) $; \mathrm{H}_{\text {pop }}=$ average diversity \\
for all populations (i.e., for all the C. sinensis groups studied) $; \mathrm{H}_{\text {pop }} / \mathrm{H}_{\text {tot }}=$ proportion \\
of diversity within populations; $\left(\mathrm{H}_{\text {tot }}-\mathrm{H}_{\text {pop }}\right) / \mathrm{H}_{\text {tot }}=$ diversity between populations.
\end{tabular}




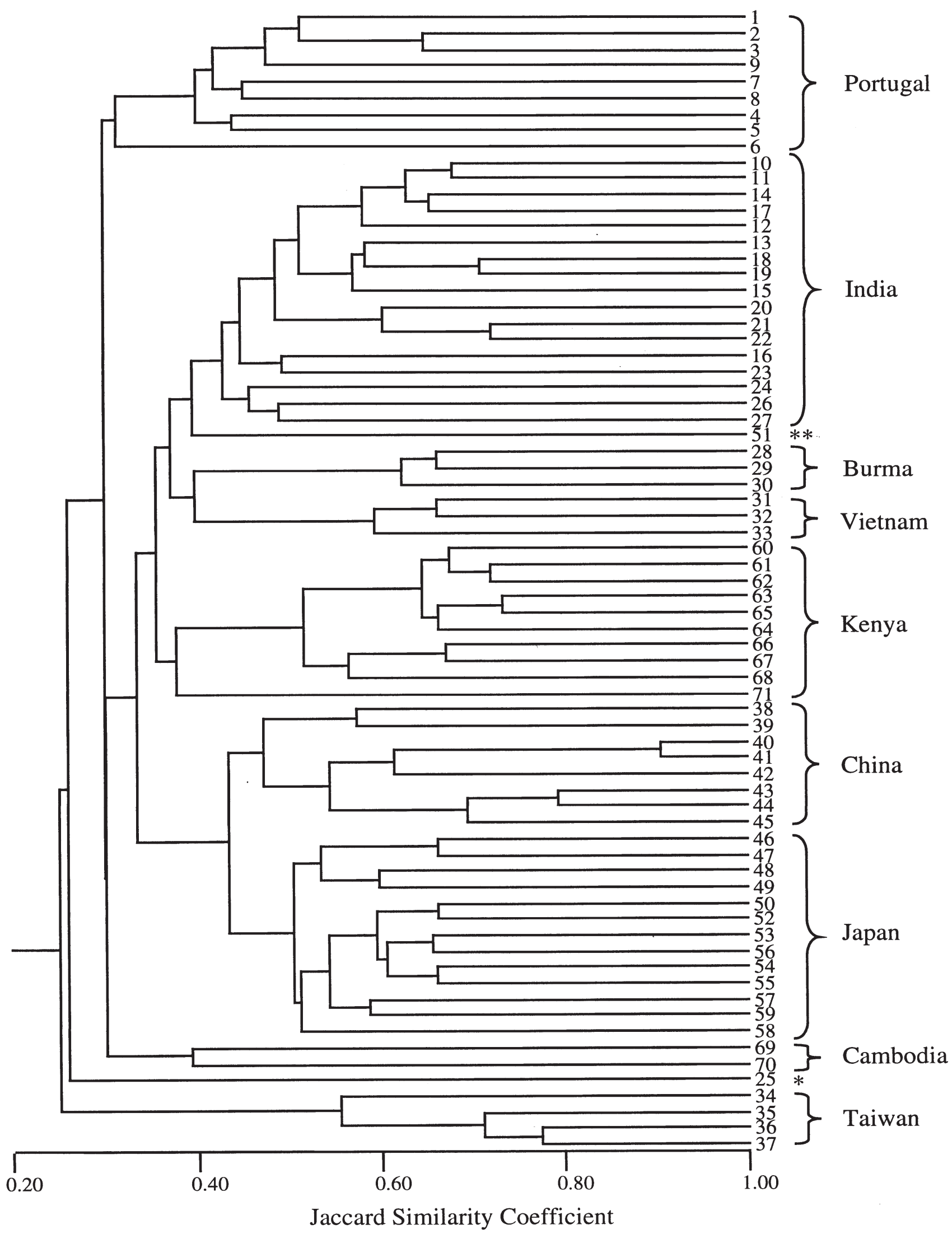

Fig. 2. Phenogram derived from 71 Camellia sinensis accessions and 195 RAPD markers using the Jaccard similarity coefficient and UPGMA cluster analysis. Asterisks show accessions where morphological features and RAPD markers give incongruent classifications (see text for details). 1 to 71 : genotype number according to Table 1 . 


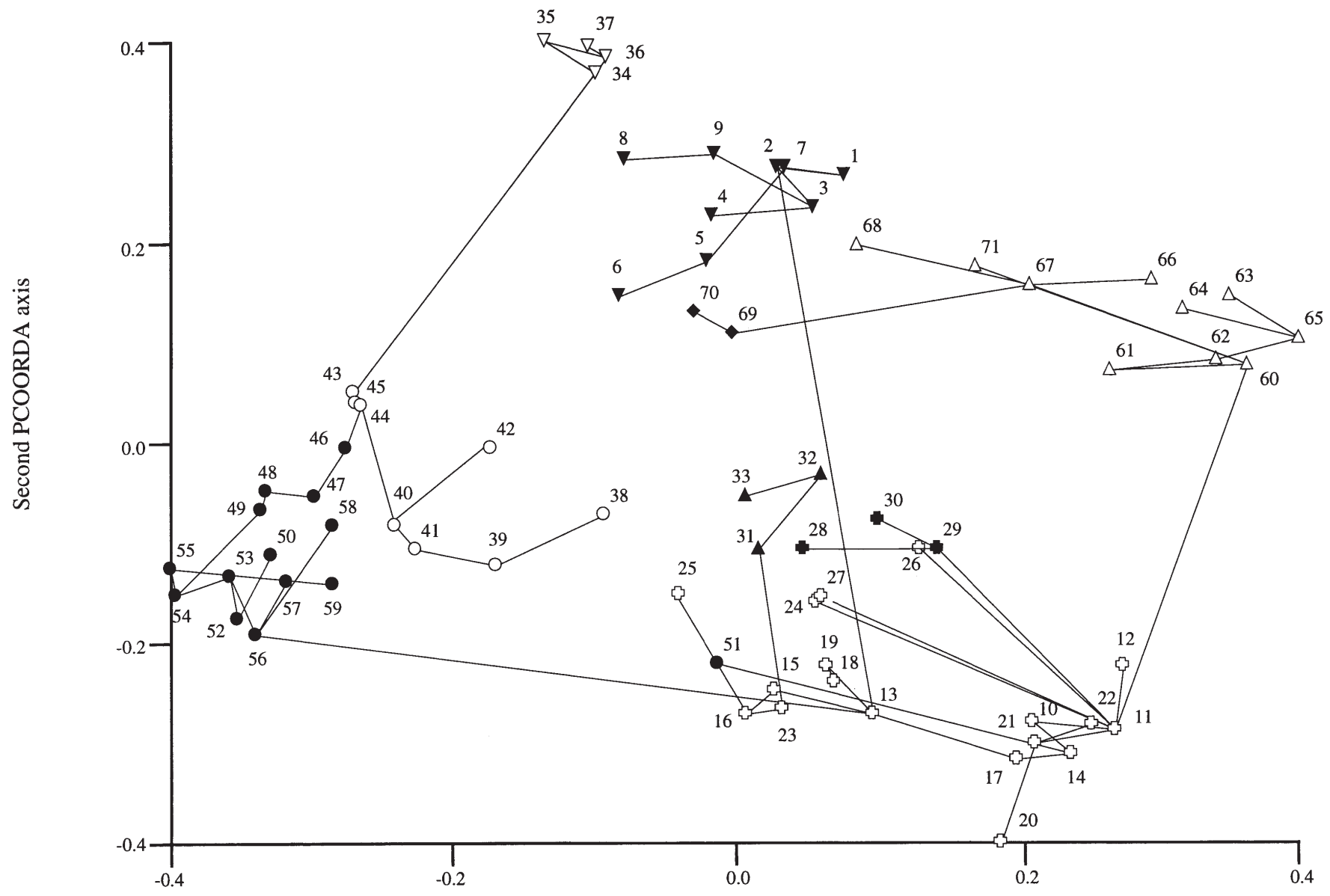

First PCOORDA axis

Fig. 3. Minimal-spanning tree (MST) superimposed on the principal coordinate analysis (PCOORDA) of Camellia sinensis based on RAPD markers. 1 to 71 : genotype number according to Table 1. $(\nabla)$ Taiwanese accessions; $(\boldsymbol{\nabla})$ Portuguese accessions; ( $)$ Cambodian accessions; $(\Delta)$ Kenyan accessions; $(\boldsymbol{\Delta})$ Vietnamese accessions; (†) Burmese accessions; (‡: open cross) Indian accessions; (○) Chinese accessions; (๑) Japanese accessions.

found for the accessions from Taiwan, Vietnam, and Burma could be due to the small size of those populations, which affects $\mathrm{H}$ values. When the genotypes were grouped according to the variety, the diversity indices ranged from 1.30 ( $C$. assamica ssp. lasiocalyx) to 2.56 (C. sinensis var. assamica). Shannon's Index, based on phenotypic frequency, was then used to partition diversity within and between these tea plant groups (Table 4); $72 \%$ of variability was found within groups, and only $28 \%$ between groups. The distribution of variability between populations varied from $11 \%$ to $42 \%$ with different primers.

Measures of similarity based on both the Jaccard and Dice coefficients and UPGMA cluster analysis were used to construct phenograms. The cophenetic correlation values obtained for each phenogram were 0.87 and 0.84 , respectively. The cophenetic correlation value can be used as a measure of goodness of fit for a cluster analysis, and the values obtained for both clusters can be interpreted as a good fit $(\mathrm{r}=0.99$ between both phenograms). Because it has a higher correlation coefficient, the phenogram obtained with the Jaccard similarity coefficient (Fig. 2) was used for the analysis.
Accession number 25 (Ai104, a variety from India) with one asterisk in Fig. 2, was distinct from the other individuals sampled in its geographical region. The Taiwanese tea accessions were grouped together by coefficients of similarity ranging from 0.54 to 0.77 , but separated from the other accessions by a coefficient of similarity of 0.25 . Two other major clusters emerged, consisting of the Portuguese tea plant accessions, with similarities ranging from 0.31 to 0.64 , and a second larger group, divided into three branches, consisting of the Indian, Chinese, and Cambodian varieties (Fig. 2). Moreover, each variety subgroup clustered according to geographical origin. The C. sinensis var. assamica accessions formed clusters from India, Burma, Vietnam, and Kenya, and the $C$. sinensis var. sinensis formed clusters from China and Japan.

Principal coordinate analysis (PCOORDA) was carried out to further discriminate the tea plant accessions. A minimum-spanning tree (MST) was computed and superimposed on the PCOORDA to help interpret the cluster analysis. As referred previously, the accession Ai104 (genotype number 25), C. sinensis var. assamica tea plant from India, was clustered separately from the remaining var. assamica accessions by the UPGMA analysis; with the ordination analysis, it was possible to ascertain its position in that group (Fig. 3). From this analysis it is also evident that the Indian, Chinese, and Cambodian varieties are clearly differentiated. Moreover, it was possible to cluster based on geographical distribution. The accessions from Japan and China formed two distinct subgroups within the var. sinensis. The same differentiation occurred within the var. assamica group, where the Kenyan accessions were clustered separately from the Indian accessions. The separation of the Vietnamese and Burmese accessions is apparent, in spite of the low number of accessions sampled. The Portuguese accessions were also unequivocally distinguished as a distant, separate group, as well as the wild tea plant accessions from Taiwan.

\section{Discussion}

The present study is the first report on the genetic relationships of Portuguese Camellia sinensis accessions. This work not only shows that RAPD analysis constitutes a good method 
to estimate genetic diversity in this economically important species, but also that it can offer valuable information about the potential taxonomic and geographic origin of unstudied accessions. DNA from different tea plant populations, amplified with arbitrary primers, exhibited a high degree of polymorphism. Our results demonstrate that the nine Portuguese tea accessions analyzed showed considerable diversity (2.35) despite the low number of accessions sampled. This high variability may reflect a relatively large genetic diversity in the $C$. sinensis plantations where these accessions originated. From all the accessions studied, the Vietnamese and Taiwanese tea plants exhibited the lowest diversity; one possible explanation is that the number of accessions studied was low and probably not representative of the available diversity of $C$. sinensis. The low diversity might also be the result of intensive selection and crossing from a genetically limited stock.

When the overall genetic diversity was partitioned, on average $72 \%$ was distributed within and $28 \%$ between tea plant groups. These values are in agreement with results previously described (Kaundun et al., 2000; Wachira et al., 1995). Camellia sinensis is an outcrossing, highly heterogeneous plant, and consequently most of the variation exhibited is within populations (Paul et al., 1997).

The placement of tea plant varieties in the phenogram is consistent with the present taxonomy of $C$. sinensis. However, the accession Yamatomidori (genotype number 51 from Japan, highlighted by two asterisks in Fig. 2), did not conform to its assumed taxonomic classification. Camellia sinensis classification has been based mostly on highly variable morphological characters. It is possible that this accession is a hybrid with morphological characters that more closely resemble C. sinensis var. sinensis, but which, genetically, is more related to $C$. sinensis var. assamica tea plants. Previous reports have also succeeded in genetically differentiating $C$. sinensis accessions at the variety level. Matsumoto et al. (1994) reported that phenylalanine ammonialyase (PAL) RFLPs allowed the differentiation of Assam hybrids and Japanese tea plants with high and low catechin content and succeeded in grouping Japanese accessions at the cultivar level. Wachira et al. (1995) and Paul et al. (1997), using RAPD and AFLP analysis, respectively, were able to distinguish commercial tea plant clones. Our results confirm that RAPD analysis is a valuable tool to study genetic diversity among $C$. sinensis varieties, enabling us to determine the genetic origin of the Portuguese (unknown) accessions.

Our study also showed that RAPD markers enabled discrimination among tea plant varieties from different geographical origins. It was possible to separate $C$. sinensis var. assamica tea plants originated from India from those from Vietnam, Burma, and Kenya, and to separate the $C$. sinensis var. sinensis accessions from China from those from Japan. The Portuguese accessions, taxonomically falling within the var. assamica, were also differentiated from the remaining Assam tea plants. Furthermore, the Portuguese tea plants were clustered further distant from the Taiwanese plants than from the Indian, Japanese, and Chinese plants. These findings are in agreement with historical data showing that the Portuguese tea plants (both from the Gorreana Plantation in Azores and from the botanical gardens in the mainland) had originated from tea seeds brought mainly from China, but also from Japan and India. This geographical differentiation may be a result of interactions of climatic and/or edaphic factors and, presumably, also due to selections made on the tea plant populations. The formation of subgroups within the China-type group, based on the geographic distribution, was reported earlier using AFLP markers, but the Assam clones, both from India and Kenya, still clustered closely (Paul et al., 1997). Semagn et al. (2000), using RAPD analysis, were also able to differentiate lowland and central populations of Phytolacca dodecandra (Endod) from those of highlands regions. Those authors explained the variation in RAPD markers mostly by the combination of the different eco-geographical variables. In our study, the observed genetic differentiation among tea-cultivating regions suggests that accessions could possibly be assigned to their regions of origin according to their genotypes. Thus, RAPD markers may be useful in determining the geographic origin of accessions of unknown background.

Interestingly, the accessions from Taiwan formed a group distinct from the remaining commercially cultivated tea plants of the var. assamica. Those wild tea accessions are distributed in the mountainous areas in central Taiwan and are not commercially cultivated. They are generally classified in the group of $C$. sinensis var. assamica because the mature leaf is large $(>10 \mathrm{~cm})$, they lack cold hardiness, and levels of chemical components, such as caffeine and catechins, are high. However, Taiwan wild tea plants are also phenotypically similar to var. sinensis in many traits, including a lack of leaf hairs on young leaves, a glabrous ovary, and coffee-fragranced leaves (Y. Takeda, NIVOT, Japan, personal communication). Thus, it is not unexpected that accessions from Taiwan were clustered separately from the remaining C. sinensis var. assamica accessions.

Camellia irrawadiensis, a wild relative of tea characterized by the presence of brickred young shoots and numerous pellucid punctuation on the leaves (Banerjee, 1992), was included in this study primarily for its suspected contribution to the genetic pool of $C$. sinensis. RAPD markers cluster this wild accession (accession 91/1) next to the tea plants originated from Kenya, with $38 \%$ similarity. Wachira et al. (1997) found that $C$. irrawadiensis showed $76 \%$ similarity with $C$. sinensis var. sinensis accession K-Purple, a commercial tea accession from Kenya that also contains characteristic red anthocyanin pigments. Those authors postulated that the cultivar K-Purple was probably a natural hybrid between $C$. sinensis var. sinensis and C. irrawadiensis. Our RAPD analysis supported this relationship, although the similarity between the previous accessions was lower (41\%).
Furthermore, as stated before, the accession K-Purple clustered together with Assam tea plants from Kenya. Nevertheless, hybridization between different $C$. sinensis taxa is a very common phenomenon, which sometimes makes it difficult to assign a clone to a particular varietal taxon (Visser et al., 1969).

The PCOORDA supported the results obtained from the UPGMA analysis and was useful in locating artifacts, like the case of the accession Ai104. In the phenogram, this accession was clustered separately from the var. assamica group but was correctly grouped by the ordination analysis. Nevertheless, the PCOORDA analysis of the accession Yamatomidori, where morphological features and RAPD profiles gave distinct classifications, conforms to UPGMA analysis. From the ordination analysis it was still possible to distinguish $C$. sinensis at the variety level and differentiate varieties according to their geographical origin.

In conclusion, RAPD markers are phenetically informative and represent a suitable method to estimate genetic variability in Camellia sinensis. RAPD data provides a high degree of resolution at the variety level and strongly suggests that genetic variability corresponds to taxonomic variety as well as geographical distribution.

\section{Literature Cited}

Amaral, J.D. 2001. O livro do chá. Temas e Debates Lda, Lisbon.

Banerjee, B. 1992. Botanical classification of tea, p. 26-48. In: K.C. Wilson and M.N. Clifford (eds.). Tea-Cultivation to consumption. Chapman \& Hall, London.

Doyle, J.J. and J.L. Doyle. 1987. A rapid DNA isolation procedure for small quantities of fresh leaf tissue. Phytochem. Bul. 19:11-15.

Edwards, K.J. 1998. Randomly amplified polymorphic DNAs (RAPDs), p. 171-175. In: A. Karp, P.G. Isaac, and D.S. Ingram (eds.). Molecular tools for screening biodiversity. Chapman \& Hall, London.

Ferrão, J.M. 1992. A Aventura das Plantas e os Descobrimentos Portugueses. Inapa. Lisbon.

Kaundun S.S., A. Zhyvoloup, and Y-G. Park. 2000. Evaluation of the genetic diversity among elite tea (Camellia sinensis var. sinensis) accessions using RAPD markers. Euphytica 115:7-16.

Kitamura, S. 1950. On tea and camellias. Acta Phytax. and Geobot. 14:56-63.

Magoma, G.N., F.N. Wachira, M. Obanda, M. Imbunga, and S.G. Agong. 2000. The use of catechins as biochemical markers in diversity studies of tea (Camellia sinensis). Genet. Resour. Crop Evolution 47:104-114.

Matsumoto, S., A. Takeuchi, M. Hayatsu, and S. Kondo. 1994. Molecular cloning of phenylalanine ammonia-lyase cDNA and classification of varieties and cultivars of tea plants (Camellia sinensis) using the tea PAL cDNA probe. Theor. Appl. Genet. 89:671-675.

Mukhtar, H. and N. Ahmad. 1999. Green tea in chemoprevention of cancer. Toxicol. Sci. 52: 111-117.

Mukhtar, H. and N. Ahmad. 2000. Tea polyphenols-Prevention of cancer and optimizing health. Amer. J. Clin. Nutr. 71:1698S-1702S.

Paul, S., F.N. Wachira, W. Powell, and R.Waugh. 1997. Diversity and genetic differentiation among populations of Indian and Kenyan tea [Camellia sinensis (L.) O. Kuntze] revealed 
by AFLP markers. Theor. Appl. Genet. 94: 253-263.

Sala, F., G. Wang, S. Castiglione, and S. Bisoffi. 1998. RAPD fingerprinting as a tool for taxonomic studies in the genus Populus, p. 447-455. In: A. Karp, P.G. Isaac, and D.S. Ingram (eds.) Molecular tools for screening biodiversity. Chapman \& Hall, London.

Sambrook, E.F., F. Fritsh, and T. Maniatis. 1989 Molecular cloning: A laboratory manual, 2nd ed. Cold Spring Harbor, New York.

Sealy, J.R. 1958. A revision of the genus Camellia. Royal Hort. Soc., London.
Semagn, K., A. Bjornstad, B. Stedje, and E. Bekele. 2000. Comparison of multivariate methods for the analysis of genetic resources and adaptation in Phytolacca dodecandra using RAPD. Theor. Appl. Genet. 101:1145-1154.

Visser, T. 1969. Tea, Camellia sinensis (L.) O. Kuntze, p. 459-493. In: F.P. Ferwarda and F. Wit (eds.). Outlines of perennial crop breeding in tropics. H Veenman \& NV Zonen, Wageningen, The Netherlands.

Wachira, F.N., W. Powell, and R. Waugh. 1997. An assessment of genetic diversity among Camellia sinensis L. (cultivated tea) and its wild relatives based on randomly amplified polymorphic DNA and organelle-specific STS Heredity 78:603-611.

Wachira, F.N., R. Waugh, C.A. Haxkett, and W. Powell. 1995. Detection of genetic diversity in tea (Camellia sinensis) using RAPD markers. Genome 38:201-210.

Weisburger, J.H. 1997. Tea and health: A historical perspective. Cancer Lett. 114:315-317.

Weising, H. 1995. DNA fingerprinting in plant and fungi. CRC Press, London.

Zar, J.H. 1999. Biostatistical analysis, 4thed. Prentice Hall, New Jersey. 